\title{
Improvement of decision-making criteria for the care of elderly cancer patients by general practitioners (Lorraine, France)
}

This article was published in the following Dove Press journal:

Clinical Interventions in Aging

\author{
Jean-Yves Niemier ${ }^{1,2}$ \\ Frédérique Claudot ${ }^{3,4}$ \\ Phi Linh Nguyen-Thi ${ }^{4}$ \\ Jean-Marie Hubert ${ }^{5}$ \\ Hubert Rousselot 2,6 \\ Athanase Benetos' \\ Christine Perret- \\ Guillaume ${ }^{1,3}$
}

'Department of Geriatric Medicine, CHRU de Nancy, Nancy, France; ${ }^{2} \mathrm{UCOG}$ Lorraine, Nancy, France; ${ }^{3} \mathrm{EA}$ 4360 APEMAC, Faculté de Médecine, Université de Lorraine, Nancy, France; 4PARC, CHRU de Nancy, Nancy, France; ${ }^{5}$ Spincourt Multidisciplinary MSP, Spincourt, France; ${ }^{6}$ SISSPO Department, Institut de Cancérologie de Lorraine, Vandœurre-lès-Nancy, France
Correspondence: Jean-Yves Niemier Department of Geriatric Medicine, CHRU de Nancy, Allée du Morvan, F54500 Vandoeuvre-Lès-Nancy, France $\mathrm{Tel}+33383154939$

$\mathrm{Fax}+3383157628$

Email jy.niemier@chru-nancy.fr
Objective: The objective of this study was to identify changes in the decision-making criteria of general practitioners (GPs) concerning the care of elderly cancer patients after 1 year of corrective measures for care practices in the Lorraine region, France.

Materials and methods: In 2014, a postal mail questionnaire was sent to all GPs in the Lorraine region. This questionnaire was designed to identify GPs' decision-making criteria. It was based on the results of a literature review and on existing guidelines. During 1 year, corrective measures were implemented to improve practices, especially training sessions for physicians and production of specific tools, including a guide to the accepted ideas in geriatric oncology. In 2015, the same questionnaire was resent to all GPs to compare the answers.

Results: In 2014, 430 questionnaires were returned out of 2,048 sent, and in 2015, 378 questionnaires were returned out of 2,066 sent. Our results show for the first time that there exists a significant difference in the overall decision criteria between the two survey periods. This difference mainly concerns criteria related to the cancerous diseases. Physicians tend to consider the principal decision criteria to be less important after the training period. GPs express the importance of accessibility to specialists for additional advice in both 2014 and 2015; the distance between the patient's home and an adapted care facility and the interval before care begins are viewed as similarly important.

Conclusion: Training and information sessions for physicians remain the most important tool for improving care practices. Such training strategies are more effective when carried out at the geographical scale at which the cancer professionals practice, allowing them to exploit their local organizational structure. The analysis of our data makes it possible to further integrate the patient into the care path, which remains a public health issue in terms of cost and organization.

Keywords: elderly, cancer, general practitioner, treatment decision-making, care improvement, older people, tumors, physician, management, ethics

\section{Introduction}

Cancer mainly affects the elderly; as the population ages, the elderly are increasingly affected by this disease. ${ }^{1}$ Cancer is the leading cause of death in patients aged 40-79 years and the second cause of death in patients aged $>80$ years. $^{2}$ The EUROCARE group has shown that, in Europe, young cancer patients' survival rates are increasing relative to the elderly. ${ }^{3}$

Management of elderly cancer patients remains difficult due to the heterogeneity of this population and the toxicities and frequent important side effects of medical treatments. Treatment must therefore extend beyond the strict care of cancer and account more for the medical, psychocognitive, and social aspects of the elderly relative to younger 
patients. For these reasons, geriatric oncology has developed both in France and worldwide.

Many factors influence the choice of care for the elderly after a suspected or confirmed cancer diagnosis. The optimal management of elderly cancer patients is hampered by a number of obstacles, including the specific medical practice, the organization of care, and the individual physician's perception of the patient as elderly. ${ }^{4}$ Among the limiting factors, some practitioners apply a certain level of tolerance. ${ }^{5}$ Different medical practices are applied according to age: cancer management is delayed for elderly patients with later diagnoses, less complete assessments, less advice from a cancer specialist, ${ }^{6}$ and unequal treatment decisions. ${ }^{7}$

The objective of our study was, first of all, to identify decision-making criteria of general practitioners (GPs) concerning the care of older people with cancer (for the categories: cancer-related decision criteria, patient-related decision criteria, decision criteria related to medical practice, and organizational decision criteria) and then their modifications after 1 year of corrective measures.

\section{Materials and methods}

This is a comprehensive cross-sectional descriptive study performed during an evaluation of GPs' professional practices in Lorraine (France).

We sent a questionnaire in an exhaustive way to all GPs in Lorraine, regardless of their mode of practice.

\section{Elaboration of the questionnaire}

The questionnaire was designed and developed in a multidisciplinary manner based on the results of a literature review and on existing guidelines in the field of geriatric oncology; some questionnaire items were reused from previous studies. ${ }^{89} \mathrm{An}$ early version of the questionnaire was tested and evaluated by a panel of liberal GPs, geriatricians of the Nancy Regional University Hospital and the Lorraine Cancerology Institute, and cancer specialists. The final version of the questionnaire comprised three sections: 1) demographics and physician qualifications; 2) the importance (not very important, somewhat important, or very important) of factors influencing the care of elderly patients, grouped into four categories of decision criteria related to the patient, disease, medical practice, and organization of care; and 3) the GPs' perceptions of the elderly, their knowledge of oncogeriatric structures, and open-ended questions about opportunities for improvement and solutions.

\section{Methods}

A complete list of GPs was provided by the medical order of each department in the region. Two sets of questionnaires were sent by the Lorraine Oncogeriatrics Coordination Unit (UCOG): the first was sent from July 9 to July 16, 2014, with responses received by September 15, 2014, and the second was sent from August 5 to August 12, 2015, with responses received by October 1, 2015.

\section{Corrective measures}

Between the two questionnaires (November 2014 to July 2015), corrective measures were implemented to improve practices, based on a literature review and results from the first set of questionnaires. During the same time, UCOG launched a coordinated training, awareness, and information campaign for practitioners, including:

- training and information sessions for physicians (continuing medical education, regional training day in oncogeriatrics, etc.) and the general public;

- meetings of professionals in Lorraine hospitals authorized to treat cancer, communication on the organization of care, and dissemination of guidance for best practices;

- production of a guide, To False Ideas and Good Practices, Cancer and the Elderly, with exhaustive dissemination by mail to doctors in the Lorraine region via the various councils of the Order of Physicians. This guide includes a medical and a legal part, combatting the main preconceptions that may interfere with elderly cancer management;

- development of a regional oncogeriatrics staff to communicate by audio conference on difficult medical cases; and

- in association with the Regional Health Agency, organization of outreach events in several elderly housing institutions in Lorraine to improve cancer screening among the most vulnerable elderly.

\section{Statistical analysis}

Given the completeness of the survey (questionnaires were sent to all GPs in the region), it was not necessary to calculate the minimum number of subjects required. Our data were validated by looking for inconsistencies in data input. Qualitative variables are expressed as numbers and percentages, and quantitative variables are expressed as their mean and standard deviation. For bivariate analysis between the two periods, we used the chi-square (or Fisher's exact) test to compare the observed percentages of the qualitative variables, and the Student's $t$-test to compare the observed means of the quantitative variables. The degree of significance for the overall risk of the first species was set at $5 \%$ in the bilateral situation. Owing to the completeness of the survey 
and the absence of significant differences in the main characteristics (age and sex) of the population between the two periods, multivariate analysis was not appropriate. Statistical analyses were performed using $\mathrm{SAS}^{\circledR}$ software version 9.3 (SAS Institute Inc., Cary, NC, USA).

\section{Ethics}

The revised manuscript has been approved by the ethics committee of the University Hospital of Nancy (CRENHU). The questionnaires were sent to all GPs of the Lorraine region, with a letter explaining the purpose of our investigation. Physicians who did not wish to participate in this study did not return the questionnaire in the enclosed return envelope. Therefore, completion of the questionnaire was deemed to be informed consent.

\section{Results \\ Demographics and general results}

The participation rate in our study was $21 \%$ in 2014 (430 questionnaires returned out of 2,048 sent) and $18.3 \%$ in 2015 (378 questionnaires returned out of 2,066 sent). Participants were $65.7 \%$ men (68.6\% in 2014 and $62.4 \%$ in 2015) and $34.3 \%$ women (31.4\% in 2014 and $37.6 \%$ in 2015$)$ with an average age of 54.8 years ( 55.3 years in 2014 and 54.1 years in 2015). GPs had been in practice (post-thesis) on an average of 22.2 years (22.9 years in 2014 and 21.4 years in 2015). Most $(72.8 \%)$ GPs practiced in an urban center or suburban area with a hospital center, and $20.5 \% \mathrm{GPs}$ practiced in rural areas. Most GPs worked alone (52.5\%). Physicians' formations varied: $34.9 \%$ had no specific training in geriatrics or oncology, $22.9 \%$ were trained in geriatrics, $6.9 \%$ were trained in oncology, and $33.2 \%$ had received training in both specialties.

\section{Decision criteria}

Results regarding decision criteria were significantly different between the two periods.

\section{Decision criteria based on the cancer disease}

These criteria relate to the primary cancer (type of cancer), the stage of cancer, the severity of cancer symptoms, and the difficulty in implementing treatment. All such criteria were considered important by the majority of physicians in 2014, but played a much smaller part in their decisions in 2015 (Table 1).

\section{Patient decision criteria}

Patient's wishes, quality of life, and comorbidities were the three criteria most frequently expressed to be the most
Table I Cancer-related decision criteria

\begin{tabular}{|c|c|c|c|c|c|c|}
\hline \multicolumn{2}{|c|}{$\begin{array}{l}\text { Factors influencing the care } \\
\text { of elderly patients }\end{array}$} & \multicolumn{2}{|c|}{$\begin{array}{l}2014 \\
(n=430)\end{array}$} & \multicolumn{2}{|c|}{$\begin{array}{l}2015 \\
(n=378)\end{array}$} & \multirow[t]{2}{*}{$p$-value ${ }^{a}$} \\
\hline & & $\mathbf{n}$ & $\%$ & $\mathbf{n}$ & $\%$ & \\
\hline \multirow{3}{*}{$\begin{array}{l}\text { Primary cancer } \\
\text { (type of cancer) }\end{array}$} & Not very in & 53 & 12.3 & 10 & 2.6 & \\
\hline & Som & 158 & 36.7 & 284 & 75.1 & \\
\hline & Very & 219 & 50.9 & 84 & 22.2 & \\
\hline \multirow[t]{3}{*}{ Stage of cancer } & Not & 45 & 10.5 & 15 & 4.0 & \\
\hline & Som & 112 & 26.0 & 275 & 72.8 & $<0.000$ I \\
\hline & Very & 273 & 63.5 & 88 & 23.3 & \\
\hline & Not & 47 & 10.9 & 234 & 61.9 & \\
\hline & Some & 120 & 27.9 & 69 & 18.3 & $<0.0001$ \\
\hline ns & Very $\mathrm{i}$ & 263 & 61.2 & 75 & 19.8 & \\
\hline & Not very import & 25 & 5.8 & 10 & 2.6 & \\
\hline & Somew & 108 & 25.1 & 189 & 50.0 & $<0.0001$ \\
\hline treatment & Very important & 297 & 69.1 & 179 & 47.4 & \\
\hline
\end{tabular}

Note: aFisher's exact test.

important by GPs in 2014; these criteria were emphasized less in 2015. Other criteria considered important by a majority of physicians in 2014 also became less important in 2015: autonomy of the patient, presence of cognitive impairment, and side effects of cancer treatment. Regarding the patient's nutritional status, $56 \%$ of GPs considered it important in 2014, whereas all GPs considered it to be unimportant in 2015. Most physicians considered the patient's chronological age unimportant in both years. However, nearly half of the GPs expressed the patient's apparent age to be important in 2014, and most considered it to be somewhat important in 2015 (Table 2).

\section{Decision criteria for medical practice}

The three decision criteria related to medical practice are implementation of good practice guidelines, access to palliative care, and access to specialists for additional advice. Access to palliative care was generally considered to be less important in 2015 compared to 2014. Three-quarters of GPs expressed the importance of available specialists for additional advice in both 2014 and 2015 (Table 3).

\section{Organizational decision criteria}

The three organizational criteria most often expressed to be important by GPs in 2014 are the absence of caregivers or social isolation, the coordination of the different contributors in the paramedical organization, and the accessibility to results and reports; each of these criteria was less emphasized in 2015. The majority of doctors reported that the interval before care is started and accessibility to a local care network were important in 2014; these criteria were similarly (accessibility to local care network) or more often 
Table 2 Patient-related decision criteria

\begin{tabular}{|c|c|c|c|c|c|c|}
\hline \multicolumn{2}{|c|}{$\begin{array}{l}\text { Factors influencing the care } \\
\text { of elderly patients }\end{array}$} & \multicolumn{2}{|c|}{$\begin{array}{l}2014 \\
(n=430)\end{array}$} & \multicolumn{2}{|c|}{$\begin{array}{l}2015 \\
(n=378)\end{array}$} & \multirow[t]{2}{*}{$p$-value ${ }^{a}$} \\
\hline Patient's & Not very important & $\begin{array}{l}\mathbf{n} \\
124\end{array}$ & $\begin{array}{l}\frac{\%}{28.8} \\
2\end{array}$ & $\begin{array}{l}\mathbf{n} \\
231\end{array}$ & $\begin{array}{l}\% \\
2.1\end{array}$ & \\
\hline chronological & Somewhat important & 217 & 50.5 & 139 & 61.1 & $<0.000$ I \\
\hline age & Very important & 89 & 20.7 & 139 & 36.8 & \\
\hline Patient's & Not v & 91 & 21.2 & 8 & 2.1 & \\
\hline \multirow[t]{2}{*}{ apparent age } & Somewhat important & 128 & 29.8 & 314 & 83.1 & $<0.0001$ \\
\hline & Very & 211 & 49.1 & 56 & 14.8 & \\
\hline Comorbidities/ & Not very & 30 & 7.0 & 8 & & \\
\hline \multirow[t]{2}{*}{ polypharmacy } & Somewhat important & 102 & 23.7 & 279 & 73.8 & $<0.00$ \\
\hline & Very & 298 & 69.3 & 91 & 24.1 & \\
\hline e & Not & 34 & 7.9 & 8 & 2.1 & \\
\hline of cognitive & Somewhat & 134 & 31.2 & 231 & 61.1 & $<0.0001$ \\
\hline impairment & Very important & 262 & 60.9 & 139 & 36.8 & \\
\hline Nutritio & Not & 39 & 9.1 & 378 & 100.0 & \\
\hline \multirow[t]{2}{*}{ status } & Some & 151 & 35.1 & 0 & 0.0 & 0001 \\
\hline & Ver & 240 & 55.8 & 0 & 0.0 & \\
\hline Patient's & Not & 25 & 5.8 & 7 & 1.9 & \\
\hline \multirow[t]{2}{*}{ quality of life } & Som & 99 & 23.0 & 319 & 84.4 & $<0.000$ I \\
\hline & Very & 306 & 71.2 & 52 & 13.8 & \\
\hline Side effects & Not very important & 30 & 7.0 & 8 & 2.1 & \\
\hline of cancer & Somewhat important & 167 & 38.8 & 222 & 58.7 & $<0.0001$ \\
\hline trea & Very & 233 & 54.2 & 148 & 39.2 & \\
\hline Patient's & Not very important & 24 & 5.6 & 8 & 2.1 & \\
\hline \multirow[t]{2}{*}{ autonomy } & Somewhat important & 142 & 33.0 & 261 & 69.0 & $<0.000$ \\
\hline & Very & 264 & 61.4 & 109 & 28.8 & \\
\hline Patient's & Not very important & 32 & 7.4 & 9 & 2.4 & \\
\hline level of & Somewhat important & 190 & 44.2 & 210 & 55.6 & 0.0001 \\
\hline understa & Very important & 208 & 48.4 & 159 & 42.1 & \\
\hline Patient's & Not very important & II & 2.6 & 9 & 2.4 & \\
\hline \multirow[t]{2}{*}{ wishes } & Somewhat importz & 69 & 16.0 & 326 & 86.2 & $<0.0001$ \\
\hline & Very important & 350 & 81.4 & 43 & 11.4 & \\
\hline \multirow[t]{3}{*}{ Family opinion } & Not very important & 25 & 5.8 & 9 & 2.4 & \\
\hline & Somewhat important & 244 & 56.7 & 126 & 33.3 & $<0.000$ I \\
\hline & Very important & 161 & 37.4 & 243 & 64.3 & \\
\hline
\end{tabular}

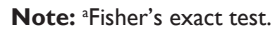

(time interval before care) reported as important in 2015. The distance between the patient's home and the adapted care structure was expressed as more important in 2015 than in 2014 (Table 4).

Table 3 Decision criteria related to medical practice

\begin{tabular}{|c|c|c|c|c|c|c|}
\hline \multicolumn{2}{|c|}{$\begin{array}{l}\text { Factors influencing the care } \\
\text { of elderly patients }\end{array}$} & \multicolumn{2}{|c|}{$\begin{array}{l}2014 \\
(n=430)\end{array}$} & \multicolumn{2}{|c|}{$\begin{array}{l}2015 \\
(n=378)\end{array}$} & \multirow[t]{2}{*}{$p$-value ${ }^{a}$} \\
\hline & & $\mathbf{n}$ & $\%$ & $\mathbf{n}$ & $\%$ & \\
\hline Implementation & Not very important & 24 & 5.6 & 12 & 3.2 & \\
\hline of good practice & Somewhat important & 143 & 33.3 & 232 & 61.4 & $<0.0001$ \\
\hline guidelines & Very important & 263 & 61.2 & 134 & 35.4 & \\
\hline Access to & Not very important & 16 & 3.7 & 10 & 2.6 & \\
\hline \multirow[t]{2}{*}{ palliative care } & Somewhat important & 103 & 24.0 & 272 & 72.0 & $<0.0001$ \\
\hline & Very important & 311 & 72.3 & 96 & 25.4 & \\
\hline Accessibility to & Not very important & 18 & 4.2 & II & 3.0 & \\
\hline specialists for & Somewhat important & 79 & 18.4 & 82 & 22.5 & $<0.000$ I \\
\hline additional advice & Very important & 333 & 77.4 & 272 & 74.5 & \\
\hline
\end{tabular}

\section{Oncogeriatric management}

GPs expressed that the accessibility of oncogeriatric assessments significantly increased between 2014 and 2015, as the possibilities for consultations rose from $27.2 \%$ to $41.3 \%$ $(p<0.0001)$. Interest in referring patients for oncogeriatric evaluations remained roughly the same $(82.1 \%$ in 2014 and $80.4 \%$ in 2015). Approximately half of the GPs (54\% in 2014 and $48.9 \%$ in 2015) reported a need for training in geriatric oncology.

In 2015, 19.8\% of GPs reported that their perception of the elderly had changed and $15 \%$ of GPs had modified their care for elderly cancer patients. The guide to false preconceptions and real good practices in oncology for the elderly was found to be useful by $84.4 \%$ of respondents. In $2014,40.5 \%$ of physicians perceived patients to be elderly after 75 years of age, whereas $46.1 \%$ of physicians considered elderly patients to be those older than 80 years in 2015 .

\section{Discussion}

Our study evaluates the decision-making criteria applied by GPs managing the care of elderly cancer patients in a French region and seeks to identify changes in these criteria following a year of corrective measures for care practices. Indeed, there was a significant difference in the overall decision criteria between the two survey periods, mainly concerning the criteria related to the cancerous disease. Physicians considered the patients' wishes, their quality of life, and the presence of comorbidities to be less important after the training period. Three-quarters of GPs expressed the importance of accessibility to specialists for additional advice in both 2014 and 2015; the distance between the patient's home and an adapted care facility and the interval before care begins were viewed as similarly important.

A limitation to this study is the low participation rate, which may raise concerns that the results are not representative of the study population. As it was anonymous, we did not have the possibility to resend the questionnaire or to phone physicians. For the same reasons, responders and nonresponders could not be compared regarding their demographics.

However, the characteristics of the respondent physicians are in agreement with those of medical demographic data in Lorraine in 2013, particularly concerning mean age (physicians who work regularly in Lorraine are 52 years old), and $60 \%$ are males. ${ }^{10}$ The type of practice $(52.5 \%$ working alone in liberal activity) is also in line with the regional figures. ${ }^{10}$ It is therefore plausible that the practitioners who replied to the questionnaire are representative of their population. 
Table 4 Organizational decision criteria

\begin{tabular}{|c|c|c|c|c|c|c|}
\hline \multicolumn{2}{|c|}{ Factors influencing the care of elderly patients } & \multicolumn{2}{|c|}{$2014(n=430)$} & \multicolumn{2}{|c|}{$2015(n=378)$} & \multirow[t]{2}{*}{ p-value ${ }^{a}$} \\
\hline & & $\mathbf{n}$ & $\%$ & $\mathbf{n}$ & $\%$ & \\
\hline Distance between the & Not very important & 67 & 15.6 & 11 & 2.9 & \\
\hline patient's home and the & Somewhat important & 182 & 42.3 & 114 & 30.2 & $<0.0001$ \\
\hline adapted care structure & Very important & 181 & 42.1 & 253 & 66.9 & \\
\hline Absence of caregivers or & Not very important & 17 & 4.0 & 8 & 2.1 & \\
\hline \multirow[t]{2}{*}{ social isolation } & Somewhat important & 82 & 19.1 & 268 & 70.9 & $<0.0001$ \\
\hline & Very important & 331 & 77.0 & 102 & 27.0 & \\
\hline Accessibility to a local care & Not very important & 30 & 7.0 & 12 & 3.2 & \\
\hline \multirow[t]{2}{*}{ network } & Somewhat important & 172 & 40.0 & 166 & 43.9 & 0.0401 \\
\hline & Very important & 228 & 53.0 & 200 & 52.9 & \\
\hline Accessibility to results & Not very important & 25 & 5.8 & 10 & 2.6 & \\
\hline \multirow[t]{2}{*}{ and reports } & Somewhat important & 113 & 26.3 & 240 & 63.5 & $<0.0001$ \\
\hline & Very important & 292 & 67.9 & 128 & 33.9 & \\
\hline Coordination of the & Not very important & 14 & 3.3 & 11 & 2.9 & \\
\hline different contributors in the & Somewhat important & 107 & 24.9 & 234 & 61.9 & $<0.0001$ \\
\hline paramedical organization & Very important & 309 & 71.9 & 133 & 35.2 & \\
\hline \multirow[t]{3}{*}{ Delay before treatment } & Not very important & 24 & 5.6 & 18 & 4.8 & \\
\hline & Somewhat important & 135 & 31.4 & 42 & II.I & $<0.0001$ \\
\hline & Very important & $27 \mid$ & 63.0 & 318 & 84.1 & \\
\hline
\end{tabular}

Note: aFisher's exact test.

Moreover, the questionnaires were sent in an exhaustive way to all GPs in the Lorraine region, so it limits the risk of bias.

Another limitation is the quantitative nature of the questionnaire, which may be a barrier to the expression of physicians. However, doctors were free to express themselves concerning any difficulties encountered and the solutions to be applied. Furthermore, we performed a complementary qualitative study of GPs and elderly people in charge of oncogeriatric consultation (in preparation).

A strong point of this study is that it is a comprehensive descriptive study, as all the GPs in the region were addressed by the questionnaire twice, roughly a year apart. We further note that post-thesis practice is on an average of 22.2 years in this survey, reflecting a great wealth of personal experience among these physicians.

Other practical studies have been performed in other regions of France to assess the links between GPs and hospital oncologists. ${ }^{89}$ Our data on medical practices are broadly consistent with previous results, notably on the importance of training. To our knowledge, no previous study has compared the decision-making criteria applied by GPs to the care of elderly cancer patients before and after corrective measures of practice.

These corrective measures follow actions already performed in other areas of care. ${ }^{11}$ First, they are focused on educating physicians about the characteristics of the elderly while combatting misconceptions. Indeed, many therapeutic decisions are made according to the personal convictions of doctors, impacting the time taken to begin treatment for their patients. ${ }^{12}$ To this end, we developed a guide to the accepted ideas in geriatric oncology ${ }_{13}^{13}$ and it has been widely disseminated to all GPs in the region; $84.4 \%$ have found it useful.

It is necessary to make doctors aware of the influence of their feelings on their strategies for caring for the elderly. These may in fact oscillate between a too-rigorous adherence to guidelines and a certain laxity in their implementation. The difficulty lies in the fact that there is no single specific management strategy for elderly cancer patients, and different care paths depend on neoplastic pathologies. GPs can find complex situations difficult to manage; access to consensus conferences, benchmarks, and results of recent clinical trials (as we have facilitated here) allows them to improve their practices. Easier recourse to multidisciplinary discussion further improves decision-making in complex situations. We have thus created an oncogeriatrics meeting to improve exchanges between oncologists, geriatricians, palliative care specialists, and GPs.

\section{Cancer-related decision criteria}

The majority of doctors considered decision criteria related to the cancer disease important in 2014, but these criteria were less often considered important in 2015. It is likely that the corrective measures put in place allowed GPs to overcome any preconceived perceptions of cancer in elderly subjects and take less account of them in the management of 
these patients. GPs often must decide if it is necessary to go further in a management plan in light of important frailties sometimes encountered in elderly subjects: inadequate social support, a patient's difficulty to understand, and significant comorbidity, which contraindicates certain treatments (renal failure, cardiac pathology); they are all arguments for not initiating a specific treatment. Gathering information and thoroughly evaluating these different parameters take time and require multidisciplinary work, justifying further oncogeriatric development. The development of geriatric oncology in France remains a model to the world, partly linked to the structuring of UCOG. These units have four main missions: ${ }^{14}$ 1) to better adapt treatments of elderly cancer patients via joint oncologist-geriatric decisions; 2) to promote the care of these patients and make such care accessible to all; 3) to contribute to the development of oncogeriatric research; and 4) to support oncogeriatric training and education.

The significant difference observed between the 2014 and 2015 questionnaire results relates to the greater importance attributed to the severity of cancer-related symptoms in 2014 compared to 2015. We know that the management of elderly cancer patients should not be based solely on repercussions of the cancer through symptoms. Indeed, the natural history of cancer shows that this pathology will continue to develop and that other complications may occur. Among the training tools we disseminated during the year between the two questionnaires, we provided a list of ten cancer-related alert symptoms based on previous literature results. The goal is to diagnose cancer as early as possible, because there is too often a delay in the start of care for the elderly.

\section{Patient-related decision criteria}

Patient's wishes, quality of life, and comorbidities were the criteria most often expressed to be important by GPs. Patient's wishes are not always in line with those of his (her) family or doctor, and evaluation of quality of life in everyday practice is often subjective and difficult to achieve; studies are underway to better understand these criteria. All other criteria considered important by a majority of physicians in 2014 were less often expressed to be important in 2015.

Opportunities may be lost when GPs rely on their perception of the patient, limiting cancer management in the case of, eg, advanced age or cognitive impairment. We therefore estimate that the training provided between the questionnaires, explaining the particularities of the elderly and the need to continue assessment, was effective. Only the nutritional status criterion, which can aggravate frailties in cases of malnutrition, dropped in perceived importance among
GPs: $56 \%$ of GPs considered it important in 2014, whereas all respondents considered it not to be important in 2015. We have found no convincing explanation for this, as it goes against the information disseminated.

We estimate that perception of the elderly evolved in the desired direction. After just 1 year, 19.8\% of GPs believed that their perception of the elderly had changed and $15 \%$ of GPs had changed their care practices for elderly cancer patients. Similarly, in 2014, 40.5\% of GPs considered a patient to be elderly after 75 years of age, whereas in 2015 , $46.1 \%$ of GPs did not consider a patient to be elderly until 80 years of age. Geriatric assessment in oncology assists physicians in complex situations by proposing appropriate geriatric care, regardless of the age of the subject. ${ }^{14}$ The most widely used geriatric oncology frailty screening tool in France is the G8 scale. ${ }^{15}$ After the G8 evaluation, three subgroups of patients and three different approaches to cancer therapy can be identified. ${ }^{16,17}$ The actual impact of this geriatric assessment for patients $>75$ years in oncology is being studied throughout France, although its effectiveness in detecting fragility has been demonstrated. ${ }^{18}$ The use of such oncogeriatric evaluations was among the improvements suggested by the doctors interviewed herein.

\section{Decision criteria related to medical practice}

There are some taskforce recommendations for elderly cancer patients in specific care situations (eg, chemotherapy protocols, surgery, etc.). There are recommendations for the use of comprehensive geriatric assessment (CGA) in older cancer patients (recommendations from the task force on CGA of the International Society of Geriatric Oncology [SIOG]); it applies to geriatric professionals.

To our knowledge, there are no general guidelines for the management of older cancer patients in community medicine.

Three-quarters of GPs in both 2014 and 2015 expressed the importance of accessibility to specialists for additional advice. There are obviously disparities in the provision of oncological care, with geographical areas understaffed in oncology consultation or plagued by long delays in obtaining appointments, even in large hospitals. Care paths have been created for certain cancers (eg, breast cancer), allowing for timely optimization and ease of access. For oncogeriatric assessments, although the number of professionals trained in Lorraine has increased threefold over 3 years, there remain too few practitioners in relation to the needs of the population. 


\section{Organizational decision criteria}

Decision-making criteria related to the organization of care were emphasized less in 2015 than in 2014. Only the criteria concerning the distance between the patient's home and the adapted care structure and the amount of time before treatment is started were expressed to be more important in 2015. Solutions proposed in the questionnaire summarized the points addressed during our training events to simplify the treatment plan; they proposed the creation of a dedicated telephone line, mail service, or coordinating nurse post in the hospitals. Another suggestion was that of an initial evaluation by a geriatrician to better guide the patients through their care plan.

\section{Conclusion}

Variations over the course of our survey suggest a lower emphasis on the main decision-making criteria for oncogeriatric care in 2015 relative to 2014. Training thus remains an important way to change the opinions of the GPs as we have been able to demonstrate, thus allowing an improvement of the care practices. It is more effective than organizational measures $^{6}$ and financial measures (which may impact the number of patients included but not the quality or adequacy of the orientation). Such training strategies are more effective when carried out at the geographical scale at which the cancer professionals practice, allowing them to exploit their local organizational structure.

Given the short 1-year interval between the two questionnaires reported herein and further training and awarenessraising events, a new evaluation should be performed to monitor their effectiveness over a greater timespan. Other health professionals should be included in these training sessions, including pharmacists and home-based professionals. We must not forget, of course, the patients themselves and their families, particularly in the framework of therapeutic education sessions that are currently in full development. ${ }^{19,20}$

\section{Acknowledgments}

Through a UCOG national program, the National Cancer Institute has allocated a budget to the University Hospital of Nancy and ICL Alexis Vautrin to study and develop the theme of cancer and the elderly. This dynamic has helped to organize teams to conduct studies in Lorraine and improve medical practices to better care for elderly patients with cancer.

\section{References}

1. Mell LK, Mundt AJ. Radiation therapy in the elderly. Cancer J. 2005; 11(6):495-505.

2. Jemal A, Siegel R, Xu J, Ward E. Cancer statistics, 2010. CA Cancer J Clin. 2010;60(5):277-300.

3. Quaglia A, Capocaccia R, Micheli A, Carrani E, Vercelli M. A wide difference in cancer survival between middle aged and elderly patients in Europe. Int J Cancer. 2007;120(10):2196-2201.

4. Terret C, Zulian GB, Naiem A, Albrand G. Multidisciplinary approach to the geriatric oncology patient. J Clin Oncol. 2007;25(14):1876-1881.

5. Neuzillet Y, Méjean A, Lebret T. Oncogeriatric evaluation for elderly patients suffering from metastatic urologic malignancies. Prog Urol. 2008;18(Suppl 7):S415-S425.

6. Akbari A, Mayhew A, Al-Alawi MA, et al. Interventions to improve outpatient referrals from primary care to secondary care. Cochrane Database Syst Rev. 2008;(4):CD005471.

7. Heitz D, Castel-Kremer É. Disparités et inégalités en cancérologie du sujet âgé [Inequalities in oncology with elderly patients]. Rev Francoph Psychooncol. 2006;5(2):85-88. French.

8. Kurtz J-E, Heitz D, Enderlin P, et al. Geriatric oncology, general practitioners and specialists: current opinions and unmet needs. Crit Rev Oncol Hematol. 2010;75(1):47-57.

9. Delva F, Soubeyran P, Rainfray M, Mathoulin-Pélissier S. Referral of elderly cancer patients to specialists: action proposals for general practitioners. Cancer Treat Rev. 2012;38(7):935-941.

10. conseil-national.medecin.fr [homepage on the Internet]. La démographie médicale en région lorraine Situation en 2013 [cited Aug 30, 2017]. Available from: http://www.conseil-national.medecin.fr/. Accessed November 10, 2017.

11. Touglo L. Médecins généralistes et patients hypertendus de plus de 80 ans. Prise en charge optimale, facteurs limitants et mesures correctives [Thèse de D.E.S de Médecine Générale]. Paris: Université Denis Diderot- Paris 7; 2009. Available from: http://www.bichat-larib. com/publications.documents/3425_THESE-TOUGLO.pdf. Accessed January 9, 2018

12. Kirwan JMJ, Tincello DG, Herod JJO, Frost O, Kingston RE. Effect of delays in primary care referral on survival of women with epithelia ovarian cancer: retrospective audit. BMJ. 2002;324(7330):148-151.

13. Niemier JY, Perret-Guillaume C, Garbacz L, Pagani V, Claudot F. Overcoming common misconceptions in geriatric oncology - medical and legal aspects in France and in Canada. Can Fam Physician. 2017.

14. e-cancer.fr [homepage on the Internet]. L'évaluation gériatrique en cancérologie - Oncogériatrie. Institut National Du Cancer [cited Jul 23, 2017]. Available from: http://www.e-cancer.fr/. Accessed July 23, 2017.

15. Soubeyran P, Bellera C, Goyard J, et al. Screening for vulnerability in older cancer patients: the ONCODAGE prospective multicenter cohort study. PLoS One. 2014;9(12):e115060.

16. Balducci L, Extermann M. Management of cancer in the older person: a practical approach. Oncologist. 2000;5(3):224-237.

17. Hurria A, Wildes T, Blair SL, et al. Senior adult oncology, version 2.2014: clinical practice guidelines in oncology. J Natl Compr Canc Netw. 2014;12(1):82-126.

18. Kirkhus L, Šaltyte Benth J, Rostoft S, et al. Geriatric assessment is superior to oncologists' clinical judgement in identifying frailty. Br J Cancer. 2017;117(4):470-477.

19. Rigdon AS. Development of patient education for older adults receiving chemotherapy. Clin J Oncol Nurs. 2010;14(4):433-441.

20. Halfdanarson TR, Jatoi A. Oral cancer chemotherapy: the critical interplay between patient education and patient safety. Curr Oncol Rep. 2010;12(4):247-252.

\section{Disclosure}

The authors report no conflicts of interest in this work. 


\section{Publish your work in this journal}

Clinical Interventions in Aging is an international, peer-reviewed journal focusing on evidence-based reports on the value or lack thereof of treatments intended to prevent or delay the onset of maladaptive correlates of aging in human beings. This journal is indexed on PubMed Central, MedLine,

CAS, Scopus and the Elsevier Bibliographic databases. The manuscript management system is completely online and includes a very quick and fair peer-review system, which is all easy to use. Visit http://www.dovepress. com/testimonials.php to read real quotes from published authors. 